\title{
Intraspinal bleeding in haemophilia: successful treatment with factor VIII concentrate
}

\author{
A N N H A R VIE, G. D. O. L O W E, C. D. F O R B E S, \\ C. R. M. PRE N T I CE, A N D J . T UR N E R
}

From the University Department of Medicine, Royal Infirmary and the Institute of Neurological Sciences, Southern General Hospital, Glasgow

SUMMARY A severely affected haemophilic boy became tetraparetic as a result of a spontaneously occurring intraspinal haematoma. Myelography defined the extent of the lesion and showed it to be extradural in site. Infusion of large doses of factor VIII concentrate led to dramatic improvement and avoided the need to operate.

Intraspinal bleeding in haemophilia is extremely rare and recovery is even rarer. To date 14 cases have been recorded, and 11 of these have died. We report here a severely affected haemophilic patient who developed acute tetraparesis from spontaneous intraspinal bleeding; prompt treatment with large doses of factor VIII (antihaemophilic factor) contributed to a remarkable clinical recovery, accompanied by radiological resolution of the haematoma.

\section{Case report}

The patient was a 20 year old, severely affected haemophilic male with a baseline factor VIII level of less than $1 \%$. He was previously described when he sustained a ruptured left ureter in the Ibrox football disaster of 1970 (Forbes et al., 1971). Four days before his referral he had again been a spectator on the terraces at a football match during which he 'strained' his neck but had no direct trauma. After this he had experienced mild neck and shoulder pain which had been treated as a suspected muscular bleed with a single infusion of factor VIII concentrate (about 750 units), a dose which was sufficient to raise his plasma level to about $20 \%$ of normal. This level would normally be considered adequate for such a trivial bleed. At that time no neurological signs were apparent. However, next day he was ad-

Address for correspondence and reprint requests: Dr C. D. Forbes, University Department of Medicine, Royal Infirmary, 86 Castle Street, Glasgow G4 OSF, Scotland,

Accepted 21 May 1977 mitted with weakness of the legs and urinary retention for 12 hours.

Examination on admission showed extreme tenderness and restriction of movement of the neck and shoulders, weakness of the left leg, bilateral extensor plantar responses, and inconstant sensory loss below T8 dermatome level; a distended bladder was also palpable. Spinal cord haemorrhage was suspected and factor VIII concentrate (2750 units) infused immediately. Radiographs of skull and spine, performed with minimal movement of the head and neck, were normal. The patient's neurological condition continued to deteriorate rapidly, and within a few hours of admission he became tetraparetic, showing only minimal movement in the lower limbs and a very weak handgrip. Sensory testing showed impairment of pinprick sensation below the C6 dermatome with no sacral segment sparing, and proprioception was impaired in the lower limbs. Bladder catheterisation was required for retention of urine. A further infusion of $\mathbf{3 0 0 0}$ units of factor VIII concentrate was given to maintain haemostasis. Myelography (Dr J. L. Steven) revealed complete obstruction at the $\mathrm{C} 5 / \mathrm{C} 6$ vertebral level (Fig. 1), probably because of an extradural haematoma. After the myelogram, improvement was apparent on neurological examination so it was felt that operative intervention should be withheld as long as the improvement continued. A further 2000 units of factor VIII was given four hours later.

The next day the patient had less pain, and further neurological improvement was noted with 


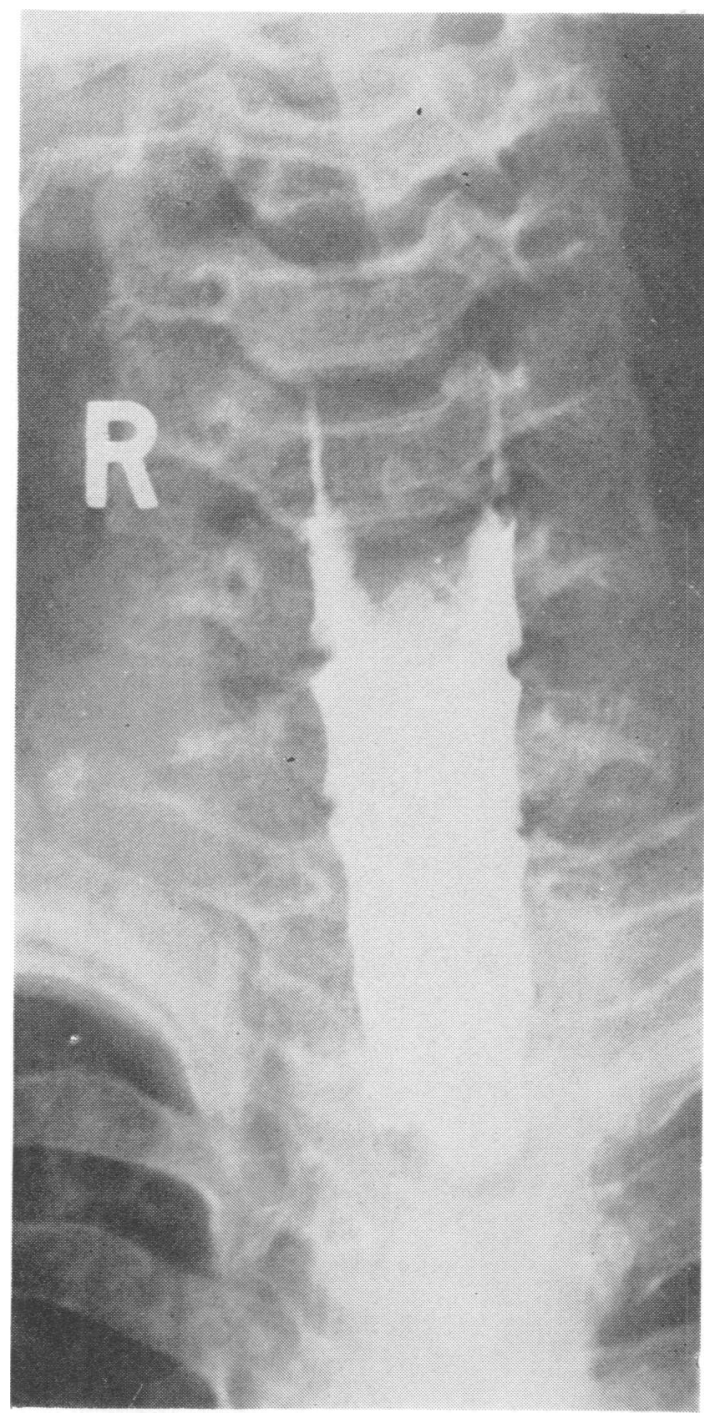

Fig. 1 Myelogram showing complete obstruction at C5/C6 spinal level due to an extradural haematoma.

increasing power in all limbs and a retreating sensory level. Factor VIII infusions were continued (3000 units twice daily, reducing to 2000 units daily) for nine days, during which his plasma factor VIII levels were maintained between 30 and $80 \%$ of normal.

During this period there was a steady improvement in motor power and sensation. Repeat myelogram after five days showed resolution of obstruction and a persistent filling defect from C6-C3 vertebrae consistent with a resolving extradural haematoma (Fig. 2). Factor VIII infusions of 1000 units daily were maintained for a further four weeks. Two weeks after removal of his catheter he developed nocturnal incontinence, and an excretion urogram showed a small volume of residual urine on the post-micturition film. Cystometry revealed disordered bladder function consistent with spinal cord damage; cystoscopy was normal. His symptoms persisted despite carbachol therapy but slowly improved to full recovery over the next few months.

During mobilisation intermittent episodes of neck pain were treated with factor VIII infusions. He was discharged home seven weeks after admission with normal muscle power and sensation (apart from residual sensory loss from an old right sided femoral nerve palsy).

\section{Discussion}

Haemorrhage into the vertebral canal in patients with a bleeding diathesis is excessively rare and a review of the literature shows only 14 such cases from 1850 to date (Tellegen, 1850; Mamoli et al., 1976; Van Trotsenburg, 1976). Of these only eight were adequately documented as having haemophilia and had been managed with plasma or plasma concentrates. All had undergone surgical procedures to relieve pressure with uniformly poor results; four died (Sumner, 1962; Schenk, 1963; Kerr, 1964; Blauw and Schenk, 1971), and the others showed no return of function (Douglas and McAlpine, 1956; Jones and Knighton, 1958; Keely et al., 1972; and Mamoli et al., 1976).

In retrospect, from consideration of this patient, pain in the neck radiating to the shoulders in a haemophiliac should suggest neural involvement before the onset of neurological symptoms and signs; such radicular symptoms in a haemophiliac should warrant admission, observation, and intensive replacement therapy with concentrates of the appropriate factor. In this patient, rapid intensive factor VIII replacement, even when severe cord compression was apparent, produced a remarkable degree of clinical recovery accompanied by resolution of the haematoma on repeat myelography. This case report supports the main lines of treatment suggested by Van Trotsenburg (1976)firstly, immediate and intense correction of the coagulation defect; secondly, early transfer to a neurosurgical centre for myelography to determine the site of haemorrhage. It has been suggested that in patients with extramedullary haematomas there may be benefit from early surgical decompression. Early care of the paraplegic patient is also optimal in a neurosurgical centre. In dealing with such patients, however, there should be close liaison 


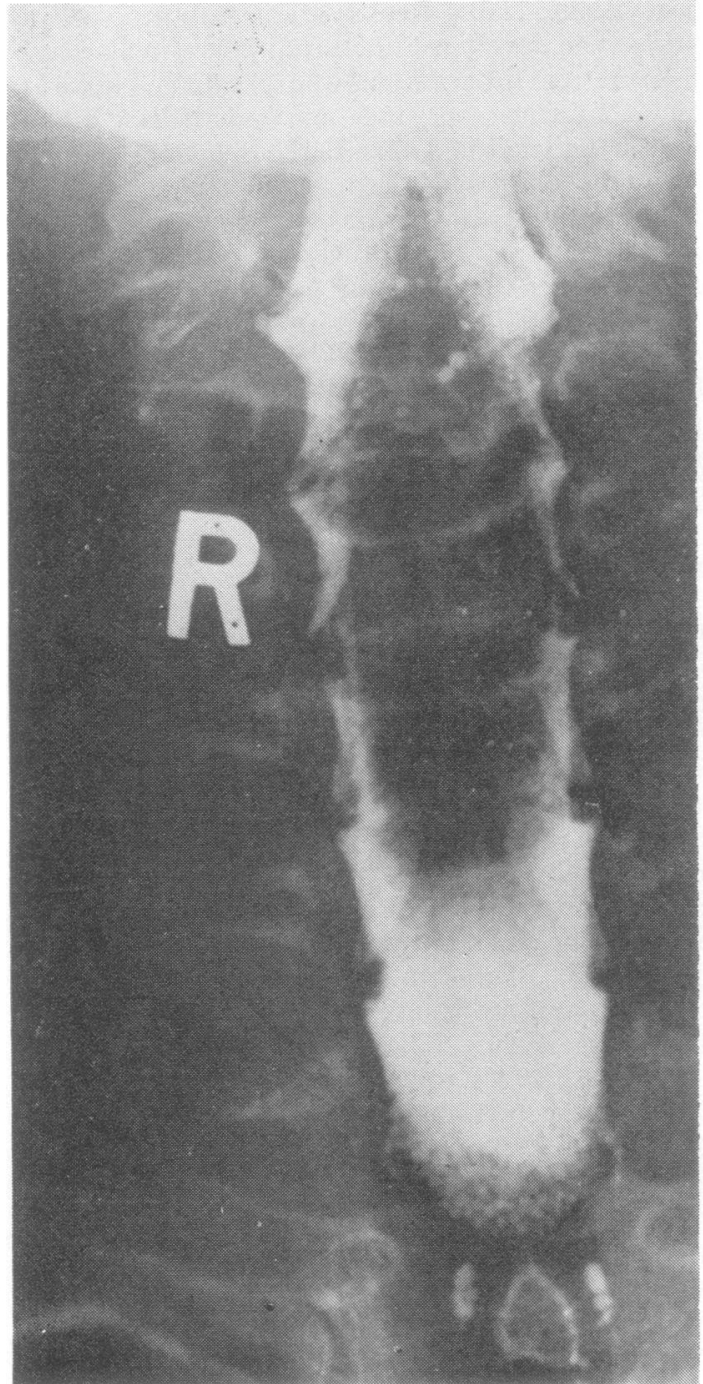

(a)

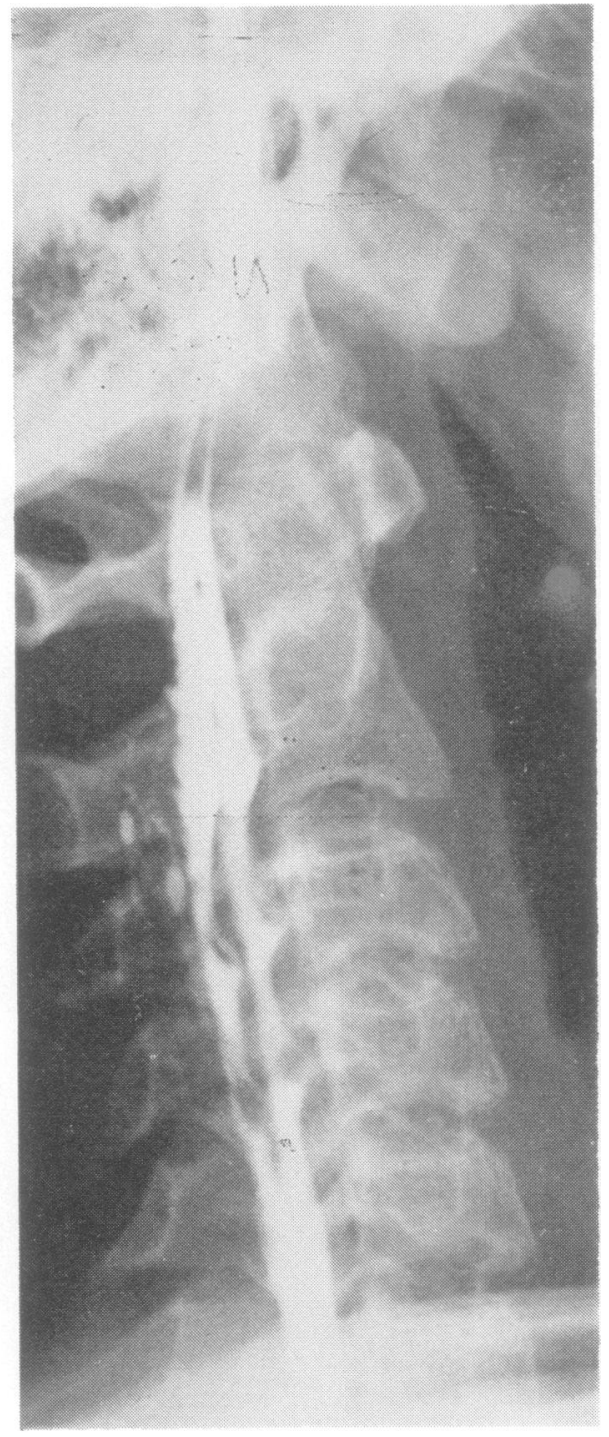

(b)

Fig. 2 Partial resolution of the haematoma with a persistent filling defect extending from C6-C3 vertebrae ( $A P$ and lateral views).

with the haematologist for the provision of adequate factor replacement to ensure haemostasis for surgery, myelography, and rehabilitation, as well as for treatment of the initial haemorrhage. Central nervous system bleeding is still the major cause of death in young haemophiliacs but with increased awareness of its importance, and the availability of potent factor concentrates, this hazard can be reduced (Forbes and Prentice, 1976).

\section{References}

Blauw, G., and Schenk, V. W. D. (1971). Cervical cord tumour in two haemophilic brothers. Journal of the Neurological Sciences, 14, 409-416.

Douglas, A. S., and McAlpine, S. G. (1956). Neurological complications of haemophilia and Christmas disease. Scottish Medical Journal, 1, 270-273.

Forbes, C. D., Craig, J. A., Prentice, C. R. M., McNicol, G. P., Levack, J. H., Ireland, J. T., Adams, J. F., and Sutherland, G. R. (1971). Rupture 
of the ureter due to crushing injury in a boy with severe haemophilia. British Journal of Surgery, $\mathbf{5 8}$, 931-934.

Forbes, C. D., and Prentice, C. R. M. (1976). Mortality in Haemophilia. Unsolved Therapeutic Problems in Haemophilia. Proceedings of the Annual Conference of the National Haemophilia Foundation. Edited by J. Fratantoni and D. L. Aronson. National Institutes of Health: Washington.

Jones, R. K., and Knighton, R. S. (1958). Surgery in hemophiliacs with special reference to the central nervous system. Annals of Surgery, 144, 1029-1032.

Keely, M. L., Taylor, N., and Chard, R. L. (1972). Spinal cord compression as a complication of haemophilia. Archives of Disease in Childhood, 47, 826-828.

Kerr, C. B. (1964). Intracranial haemorrhage in haemophilia. Journal of Neurology, Neurosurgery, and Psychiatry, 27, 166-173.

Mamoli, B., Sonneck, G., and Lechner, K. (1976). Intrakranielle und spinale Blutungen bei Hämophilie. Journal of Neurology, 211, 143-154.

Schenk, V. W. D. (1963). Haemorrhages in spinal cord with syringomyelia in a patient with haemophilia. Acta Neuropathologica, 2, 306-309.

Sumner, D. W. (1962). Spontaneous spinal extradural hemorrhage due to hemophilia. Report of a case. Neurology (Minneapolis), 12, 501-502.

Tellegen, R. J. (1850). Drie gevallen van bloederziekte, waargenomen in Drenthe en Gronigen. Nieuw Praktisch Tijdschrift voor de Geneeskunde, 2, 414416.

Van Trotsenburg, Louise (1976). Neurological complications of haemophilia. In Handbook of Hemophilia, pp. 389-404. Edited by K. M. Brinkhous and H. C. Hemker. Excerpta Medica: Amsterdam. 